\title{
DE PAI PARA FILHO: O PARADOXO FUNDAMENTAL DA MASCULINIDADE
}

\author{
André Assis Breder Oliveira \\ Universidade Federal de Minas Gerais \\ Cassandra Pereira França \\ Universidade Federal de Minas Gerais
}

\begin{abstract}
Resumo
Partindo da defesa de Silvia Bleichmar da masculinidade enquanto uma constituição que perpassa o paradoxo no qual o menino precisa, numa relação de amor, incorporar o pênis paterno para revestir de potência e legitimar sua posição sexuada, o presente artigo contempla as peculiaridades da relação paterno-filial enquanto fonte de afirmação e contradição, já que essa fantasmática identificatória será classificada pelo Eu como homossexual. As vicissitudes da relação entre filho e pai são abordadas do estádio pré-edipiano à adolescência deflagrando que os paradoxos deixados por esse laço, ainda que represente a fragilidade da identidade masculina como essencialmente defensiva, compõem uma posição mais fértil para o sujeito. O enigma de uma posição sexuada em busca de confirmação viril apresenta a conjectura de que o sujeito, buscando a solução para a falta simbólica, pode colocar em ato a fantasmática da incorporação e, assim, estar mais suscetível à submissão sexual violenta a outros homens.
\end{abstract}

Palavras-chave: identidade masculina; complexo de édipo; incorporação da masculinidade.

\section{FROM FATHER TO SON: THE FUNDAMENTAL PARADOX OF MASCULINITY}

\begin{abstract}
Silvia Bleichmar's thesis of masculinity as a constitution tied to the paradox in which the boy needs to incorporate, in an affective relationship, the paternal penis to legitimize his sexed position is the foundation to this article which contemplates the peculiarities of the father-son relationship as the source of both affirmation and contradiction, since its identificatory phantasmatic is signified by the Ego as homosexual. The vicissitudes of this relationship are approached from the pre-Oedipal stage to adolescence revealing that the paradoxes left by this bond, although representing the fragility of the masculine identity as essentially defensive, compose a more fertile position for the male individual. The enigma of a sexed position craving for virile confirmation leads to the conjecture that one, seeking solution to his identity symbolic deficiency, can put into act the phantasmatic of incorporation and thus be more susceptible to violent sexual submissions to other men.
\end{abstract}

Keywords: male identity; oedipus complex; incorporation of masculinity.

\section{DEL PADRE AL HIJO: LA PARADOJA FUNDAMENTAL DE LA MASCULINIDAD}

\begin{abstract}
Resumen
La tesis de la masculinidad, defendida por Silvia Bleichmar como una constitución que se ejecuta a través de la paradoja en la que el niño necesita, en una relación de amor, incorporar el pene paterno para revestir y legitimar su posición sexuada es el fundamento de este artículo que considera la relación paterno-filial como fuente de afirmación y contradicción. Las vicisitudes de los lazos entre niño y padre son abordadas desde el estadio pre-edípico hasta la adolescencia revelando que las paradojas que dejan este vínculo, a pesar de que representa la fragilidad de la identidad masculina como esencialmente defensiva, representan una posición más fértil para el sujeto. El enigma de una posición sexuada en busca de confirmación viril presenta la conjetura de que el sujeto, en busca de la solución a la falta simbólica, puede actuar la fantasmática de la incorporación y así estar más susceptible a la sumisión sexual violenta a otros hombres.
\end{abstract}


Palabras clave: identidad masculina; complejo de edipo; incorporación de la masculinidad.

\section{INTRODUÇÃO}

A tese desenvolvida por Silvia Bleichmar no livro "Paradojas de la sexualidad masculina" (2006) é um importante marco na superação daquilo que a própria autora define como um impasse epistêmico para a teoria freudiana: ter concebido a masculinidade como o efeito linear de uma gênese. Subvertendo a lógica que sustentava tal obstáculo e procurando diminuir a defasagem da teoria sobre os conflitos intrínsecos ao processo de tornar-se homem provocada pelo desvio da atenção da psicanálise quase exclusivamente para os mistérios do "continente negro", Bleichmar apresenta uma proposta que deflagra a profunda fragilidade da identidade masculina ao fundamentá-la em um paradoxo essencial.

A autora defende que a masculinidade perpassa um processo constitucional, um caminho bastante intrincado, o qual, apropriando-se de uma divisão didática, Bleichmar apresenta em três estádios. Primeiramente, a formação da identidade de gênero, quando o menino poderá se localizar segundo os organizadores de gênero que a cultura e a família oferecem como sendo "de menino" ou "de menina", uma divisão arbitrária, mas fundamental para que a criança se aproprie de um dos gêneros em um momento marcado pela diversidade dos parâmetros arbitrários da cultura e em que ainda não conhece a diferença binária da anatomia. No segundo momento, a partir da descoberta da diferença anatômica, o menino re-significará seu gênero segundo o entendimento de que existe um sinal em seu corpo subjacente a essa divisão; e, por fim, no terceiro estágio, o menino terá que estabelecer a qual classe de homem lhe é possível fazer parte. É em relação ao segundo momento que Bleichmar se detém apresentando o eixo de sua tese e, também, sobre o qual nos debruçaremos com afinco. Afirmando a diferença fundamental entre a simples posse do pênis enquanto objeto narcisicamente investido e a ascensão sexuada, a autora sustenta que o menino precisará, em um movimento identificatório intrínseco a uma relação de amor com um homem (estatisticamente o pai, que será, então, tomado aqui como representante), incorporar seu pênis, isto é, que a masculinidade precisa ser incorporada.

Bleichmar esclarecerá por que a passagem do primeiro tempo (a instauração da identidade de gênero) para o segundo (o da identidade sexual) representa uma mudança tão significativa. Nesse momento, a apropriação de gênero, lançando as fundações do processo de constituição ativa da masculinidade em um momento menos defensivo devido à maleabilidade característica da diversidade, dá lugar aos conflitos característicos da polaridade imposta pela diferença, pelo binarismo da anatomia: ter pênis ou ter vulva (ou 
não ter pênis) e suas implicações diretas sobre as posições sexuadas diante do objeto. Mas não se trata apenas disso. O fato é que a identidade de gênero, mesmo aportando traços secundários da masculinidade ligados aos modos de subjetivação que fornecem à criança elementos para se localizar como menino ou menina, não esgota a questão identificatória do processo de constituição da masculinidade. Mesmo re-significada a posteriori, a identidade de gênero não pode recobrir a identidade sexual porque se alicerça sobre os modos históricosociais de produção de subjetividade, os quais são insuficientes para apreender as articulações do desejo que é gerado entre os sistemas psíquicos (Bleichmar, 2006).

Aliás, na insuficiência desse recobrimento é que se encontraria o eixo que amarra as três etapas em que Bleichmar (2006) divide a constituição da masculinidade. Entre a primeira, "ser homem" (gênero), e a terceira, localizar-se entre as "classes de homens", será preciso que o órgão masculino seja revestido de uma potência que legitime o sujeito como homem sexuado, ou seja, enquanto possuidor de um pênis a ser oferecido ao objeto. Em outras palavras, tornar-se homem é um encadeamento que se alicerça fundamentalmente nesse estádio intermediário (posterior à identificação de gênero e anterior à identificação com o supereu paterno e com os ideais, herdeiros do complexo de Édipo) em que se dá a articulação que viabiliza o exercício da masculinidade. Sustentar a imprescindibilidade desse momento que sucede a apropriação de gênero significa destacar a diferença fundamental entre o objeto valorizado da diferença anatômica, que se converte em investimento fálico do pênis, e a sua função genital como órgão potente a ser oferecido e não apenas exibido (Bleichmar, 2006). É, portanto, diante desse desejo de ascensão a uma posição viril que excede a presença/ausência do pênis, que Bleichmar chega à tese de que o menino precisa, em uma relação de amor com o pai (que tomamos como representante estatístico do homem referencial para o menino), ter seu pênis investido de potência genital por meio da incorporação anal do pênis paterno.

Tal concepção proposta pela autora se alicerçaria sobre o modelo da identificação. Se, argumenta Bleichmar (2006), todo processo identificatório remete a uma introjeção como apropriação simbólica e fantasmática do objeto do qual o outro é o portador, o menino só poderia, tendo em vista a identificação prototípica do seio, receber o pênis de um homem que o torne sexualmente potente a partir de uma incorporação: "El prototipo de toda identificación es el pecho: suporte libidinal del intercambio apropiatorio con el semejante. ¿Cómo podría recibir el niño el pene de un hombre que lo torne sexualmente potente si no fuera a partir de su incorporación?" (Bleichmar, 2006, p. 35)

Nesse percurso lógico, Bleichmar (2006) sustenta também que esse processo inexorável da identidade masculina se desdobraria em duas partes: a incorporação anal fantasmática do pênis do adulto, e a legitimação da eficácia desse revestimento de virilidade e do valor do pênis que porta o "infantil sujeito" 
no olhar da mãe. Trata-se, portanto, de uma complexa articulação entre a valorização da mulher do pênis do homem e de sua relação com o do filho. Claramente, todavia, é apenas sobre a primeira que a autora realmente se debruça, procurando contemplar as vicissitudes da transmissão de potência que confirma a masculinidade e possibilita seu exercício, mas que, ao operar-se, legaria a masculinidade para sempre ao fantasma da homossexualidade. Eis, então, o paradoxo fundamental que defende: é às custas da incorporação do pênis paterno que se instaura tanto a posição viril do sujeito como, também, pela significação que o Eu atribui a essa fantasmática, a angústia homossexual e a fragilidade identitária predominante nos homens.

Ampliando os alicerces e a abrangência de sua tese ousada, Bleichmar (2006) lança mão de relatos antropológicos e históricos para realizar o que denominou de "comprovações antropológicas" de sua argumentação. De modo geral, ao evocar rituais de passagem da masculinidade, quer seja na Grécia antiga, em uma tribo da Papua Nova Guiné e mesmo na prática observada na América Latina em que os homens levam os adolescentes para serem iniciados no prostíbulo, a autora destaca que, em todos eles, o que está em jogo é que a infância e a puberdade que antecedem a iniciação do jovem o identificam com a feminilidade, com a marca deixada pela mãe, que deverá ser abandonada como identidade para que o rapaz possa fazer-se parte da comunidade masculina. Além disso, todos esses exemplos deflagram a relação conflitante entre "meio" e "fim", isto é, o fato de ser a homossexualidade, mais especificamente a fantasmática ou o próprio ato homoerótico, a via de acesso à masculinidade, tal qual enuncia Bleichmar em sua "hipótese forte".

O relato antropológico do ritual dos Sambia, em que a fantasmática incorporação do pênis é menos rica em simbolismo e colocada em ato mais "concretamente", evidencia esse movimento de purgação do feminino e subsequente incorporação da masculinidade atravessada por um ato homossexual. "Sambia" é o nome fictício que o antropólogo Gilbert Herdt deu para uma tribo da Guiné e Bleichmar (2006) se apropria das preciosidades por ele descritas em "Rituals of manhood". Segundo Herdt, os membros dessa tribo acreditam que todos possuem um órgão chamado tingu. Nas meninas, ele age desde o nascimento gradualmente as convertendo em mulheres, enquanto nos meninos, por ser fraco e inativo, precisaria que os homens adultos, alimentandoo com sua virilidade, o ajudassem crescer e a se fortalecer. É sobre a convicção de que a masculinidade precisa ser "inseminada" que tem início o que Herdt denomina "homossexualidade ritual".

Em um primeiro momento, o menino entre sete e dez anos de idade é afastado da presença materna que, considerada perniciosa, o manteria sob uma condição infantil sexualmente determinada. Em seguida, recluso em um ambiente exclusivamente masculino e pronto para que seu tingu possa ser estimulado, tem início o processo de masculinização, constituído por rituais que 
podem durar vários anos. Além das provas dolorosas como surras e, para serem limpos do sangue e do leite maternos, sangrias e vômitos, a iniciação culmina com o menino realizando felações repetidas nos pênis dos homens adultos e ingerindo o sêmen destes para criar um "lago de virilidade" que fortaleça seus ossos e desenvolva seus músculos. A convicção dos homens Sambia é de que a virilidade é um estado artificialmente induzido, de conversão de uma posição inicialmente feminina, e que, por isso, deve ser imposto aos meninos através desses rituais. Esse processo, fora de uma intenção de obter prazer por parte dos homens, estaria submetido ao objetivo prático de transmissão da masculinidade, sendo que, após a conclusão desse longo processo, as práticas homossexuais são abandonadas, isto é, com a aparição dos caracteres sexuais secundários, mais especificamente, o pelo facial.

Pois bem, o fato é que a masculinidade enquanto uma constituição tal qual defendida por Bleichmar, isto é, que precisa livrar-se das amarras da feminilidade primária e ascender a uma posição essencialmente defensiva não só em relação à posição anterior, mas ao próprio ato significado como homossexual pelo qual precisa atravessar, faz com que aspectos importantes da teoria psicanalítica clássica não se sustentem sem modificações. Entendemos que a identificação sexuada do menino, parte fundamental da constituição da masculinidade, é não apenas inconcebível sem o desejo pelo pai, mas também profundamente conflituosa e distante da simplicidade proposta que reduz a lógica à presença do pênis. Por conseguinte, a suposta linearidade dos processos identificatórios masculinos é problemática também por engessar o papel do pai como rival. O pensamento de Bleichmar (2006) indica ser preciso ampliar as qualidades dessa "presença inquietante" e da relação que envolve filho e pai já que são as monções amorosas e eróticas daquele em direção a este que, sublimadas, definem o caminho da identificação do menino, impensável se restrito ao puro antagonismo da rivalidade. Isso denuncia que ao paradoxo clássico da sexualidade masculina "ser como o pai como sujeito sexuado e não ser como o pai enquanto possuidor da mãe" (Freud, 1923) se soma outro: não sendo possível identificar-se com um puro rival, é pelas correntes ternas e eróticas do filho em relação ao pai que reside a possibilidade do menino ascender a uma posição masculina sexuada revestida de potência e legitimada ao exercício da sexualidade.

O menino precisa crer na bondade do seu órgão genital masculino e, também, na do órgão de seu pai e, dessa forma, não ter sua confiança no pai bom mitigada pelo medo do pai castrador. Assim é que ele poderá tanto se permitir experimentar desejos em relação à mãe quanto desenvolver a tendência edípica simultânea homossexual (Breen, 1998), ou seja, envolvido em uma relação de riquíssima complexidade, que não deve ser empobrecida por um olhar unilateral, uma vez que o pai também se oferece como objeto de amor. 
Portanto, se na obra freudiana a disputa do menino edipiano com seu pai, uma combinação de admiração, ódio mortal e pavor, ocupa lugar emblemático nos conflitos enfrentados pelo masculino, na proposta de Bleichmar em "Paradojas de la sexualidad masculina" é ainda na relação com o pai que o conflito paradigmático da masculinidade se encontra, mas em um sentido consideravelmente distinto. Tendo articulado gênero e sexo, os desejos eróticos do menino já não estão referidos ao polimorfismo e, então, o reconhecimento da genitalidade inaugura o conflito entre os traços de identidade e os desejos pulsionais do menino, obrigando-o, na maioria das vezes, a renunciar e a sepultar no inconsciente as representações dessas modalidades de desejo. Por isso, o enlace que começa desde os cuidados precoces que o pai dedica ao filho e sobre os quais se inscreverão os atuais desejos eróticos pelo pai são ressignificados a posteriori pelos fantasmas de masculinização, classificados pelo Eu como homossexuais e, logo, adquirem caráter profundamente conflitivo (Bleichmar, 2006). Em resposta ao paradoxo que impõe a incorporação do pênis paterno (símbolo de virilidade) como condição para a autorização do exercício viril, o menino rechaçará esses desejos e fantasias significados como homossexuais e se sentirá para sempre assombrado por eles. É sobre as vicissitudes dessa relação tão complexa que nos deteremos daqui em diante.

\section{A INCORPORAÇÃO DO ÉDIPO}

Os desejos incestuosos da criança pela mãe e pelo pai não são programados pela natureza ou têm sua origem ex nihilo. Se a psicanálise é alicerçada nas narrativas que as associações de cada sujeito desenham é porque o conteúdo primordial que procura abstrair é a história dos desejos, isto é, historicizar, em alguma medida, os entrelaçamentos libidinais que foram envolvendo os objetos mais relevantes nas vivências do sujeito e simultaneamente, em um processo uno, marcando seu corpo e seu psiquismo. Essa concepção que retira a sexualidade da submissão aos ciclos biológicos e a localiza nos movimentos desejantes é um entendimento que deve mérito à contribuição de Jacques Lacan. Jean Laplanche, nesse aspecto, continuou fiel ao seu primeiro mestre, colocando, com a teoria da sedução generalizada, o adquirido antes do inato, isto é, o advir do instinto, como na adolescência, inexoravelmente sitiado pelo sexual (Bleichmar, 2006).

Nesse sentido, impõe-se a necessidade de uma breve digressão para que se faça a menção adequada à sedução generalizada, teoria elementar para o pensamento de Silvia Bleichmar e que também oferece os fundamentos para a elaboração que se seguirá sobre os laços que amarram filho e pai. Em linhas gerais, Laplanche defende que a situação antropológica inexorável em que o bebê humano, completamente incapaz de garantir sua sobrevivência e dependente de cuidados, garante uma relação assimétrica na qual o adulto, 
através de mensagens comprometidas com sua própria sexualidade infantil recalcada, inocula sexualidade na criança por meio dos tratos imprescindíveis para a sobrevivência do infans. A situação originária de todo ser humano seria, portanto, a confrontação do mundo da criança com o mundo adulto, o qual não se definiria objetivamente, mas por uma linguagem, ou mensagens paralinguísticas, dos gestos e dos afetos que caracterizam essa presença sedutora (Laplanche, 1988). Em outras palavras, em todo povo ou cultura, um adulto clivado e provido de inconsciente, implanta na criança, dona de um corpo biológico excitável e da reatividade de um psiquismo em vias de constituição, conteúdos sexuais desligados. Na medida em que estas mensagens, comprometidas com a sexualidade infantil do adulto, são transmitidas e seu caráter enigmático interpela o bebê, também o corpo deste se excitaria, perderia a linearidade do biológico e sofreria uma dupla invasão: a enxurrada de significantes provenientes do exterior e o corpo que a ela responde produzindo excitações que o invadem do interior. Procurando responder a essa invasão da sexualidade do outro e traduzir seu conteúdo enigmático é que o sujeito psíquico se constituiria. Afinal, a fundação do inconsciente, pela operação do recalcamento originário, surge do imperativo de se delimitar espaços psíquicos distintos que se refiram aos resultados dos processos tradutivos: os restos não metabolizados do trânsito afetivo sexual do infante com o adulto não podem ocupar o mesmo lócuspsíquico que mensagens enigmáticas traduzidas.

Assim, considerando-se o parâmetro firme oferecido pela teoria da sedução generalizada e o fato de que, inevitavelmente, destaca que cada história é definida a partir do que Freud denominou apoio, faria toda a diferença que o enlace entre pai e filho tenha suas bases lançadas na sedução generalizada quando o adulto, mesmo enquanto outro sem diferença sexual ou de gênero, delimitará ativamente, ainda que inconscientemente, o fluir libidinal que vincula, senão os destinos, ao menos as origens do prazer (Bleichmar, 2006). Essa compreensão evidencia a importância do après-coup, ou seja, das resignificações das vivências passadas do sujeito à medida que passa por outras experiências em vez da lógica desenvolvimentista de sucessão de fases e, ao mesmo tempo, coloca a maturação biológica submetida aos sistemas representacionais que possibilitam ao sujeito assumir tal maturação. Em outras palavras, o que estaria em jogo não são as etapas isoladas da vida do sujeito, mas o fato de que tanto as vivências quanto os objetos envolvidos nas vivências mais precoces da vida do bebê serão submetidos à re-significações sucessivas trazidas pela novidade do arranjo de cada estádio - determinados de modo libidinal e não constitucionalmente.

Assim, pensar a entrada do menino no complexo de Édipo aponta para mais do que um simples acontecimento programado na linha do desenvolvimento. Essa passagem evoca todo o percurso das vivências narcísicas e os enlaces com as figuras parentais pré-edipicas, submetidas a re-sigificações, 
que o levam até esse ponto de inédita complexidade relacional - a ponto de autores dedicados às questões narcísicas, como Joyce McDougall (1989), afirmarem que, para muitos, chegar à trama edipiana é um desafio quase impossível. Com efeito, esse complexo abarca grandes eixos de identidade e diferença, desejo e proibição, ego e alteridade (Hornstein, 2009) e, inclusive, para Bleichmar (2014), se o Édipo ainda reserva importância que justifique destaque é pelo fato de ser o primeiro momento em que moções eróticas e amorosas se articulam, o que implica, consequentemente, no surgimento de um pai e uma mãe distintos dos que haviam estado presentes até então.

Apesar dessa asserção, não deve ser surpreendente, tendo atentado para suas considerações sobre a constituição da masculinidade, que a obra de Silvia Bleichmar não atribua ao Complexo do Édipo papel fundamental à compreensão do funcionamento psíquico. De fato, quando a autora aborda esse complexo, normalmente o anuncia com suas ressalvas a como é concebido em seu modelo clássico e apresentando suas objeções (Bleichmar 2006; 2014). Porém, é importante destacar que, nessa apropriação do Édipo, trata-se do complexo como proposto por Freud, isto é, como núcleo importante da vida psíquica; todavia, seria um núcleo que não apenas condensa, mas que, também, irradia, implicando o conjunto de relações da criança com seus pais desde o nascimento até a morte, pois: "Optar por uma visão determinista do Édipo e por uma história linear e não retroativa implicaria que o Édipo é somente o ponto culminante da vida sexual infantil, que não irradia para a vida posterior." (Hornstein, 2009, p.83). Além disso, não há razão em procurar encontrar no conflito edípico a origem da identidade sexual masculina, afinal, como sinalizado até aqui a partir da exposição da tese sobre a constituição da identidade masculina, sustentamos a afirmação de Bleichmar (2014) de que o Édipo não é um ponto de partida, mas o efeito da rearticulação das relações primárias com os objetos.

Nesse sentido, é preciso reconhecer os impasses teóricos impostos por se defender o Édipo como estrutura, como propôs Lacan, pois significa sustentar sua pré-existência ao sujeito que, mesmo sem o saber, estará inserido nele desde sempre. Essa é uma das maiores críticas de Bleichmar (2014) à ideia de Édipo, além de que, colocando em questão os objetos parciais a serem articulados pela posição do falo, o Édipo-estrutura suplanta o Édipo-complexo, que se torna apenas o momento do corte, da inscrição da metáfora paterna aliás, a própria noção de "complexo" é essencial para o entendimento de que o Édipo inclui elementos diversos além da forma linear de amar a mãe e odiar o pai (Bleichmar, 2010). Por outro lado, não deve ser desprezado um aspecto notável do complexo que, sem dúvida, transcende as fronteiras temporais do Édipo do menino isolado: a inserção do sujeito em uma rede geracional que remete diretamente não apenas a seu pai, mas ao pai de seu pai e assim por diante, colocando em jogo os conflitos edipianos que antecederam o seu próprio acervo como os bens herdados e a serem transmitidos. Ainda assim, evitando a 
dessexualização da psicanálise evidenciada principalmente pelo lacanismo quando se considera que apenas por razões significantes alguém elege um ou outro caminho, não ignoraremos a força da sedução erógena nesse processo de marcas transgeracionais. O trauma das origens do sujeito deve-se à invasão da sexualidade do adulto a qual, na realidade, caracteriza-se não por formas mais simbolizadas, mas sim pelo que se recusa à simbolização, de forma que é esse "não representado" o que retornaria insistentemente sob a forma de sintoma (Bleichmar, 2014).

Sendo assim, ainda que se revelem profundamente relevantes os processos pré-edipianos, destaca-se o fato de que é, sim, no interior do Édipo, postulado medular da teoria freudiana, "que se decantam e decidem a feminilidade, a masculinidade e as patologias." (Miguelez, 2012, p.13, grifo nosso). Seria, então, no sentido de um desfecho, ainda que nunca absoluto, que o Édipo se incorporaria à constituição da masculinidade, especialmente no que se refere à relação erótica com o pai a qual, como veremos, foi inaugurada ainda nos cuidados primordiais ao corpo do bebê. Ao adentrar o Édipo é que o menino, que já tem em sua bagagem os desafios de desembaraçar-se da feminilidade originária de sua sexualidade e de revestir seu gênero com virilidade, poderá encontrar, em um ápice da relação erótica com o pai, sua validação como possuidor de um órgão igualmente potente - podendo, assim, inclusive, rivalizar com ele pela posse da mãe.

Além disso, tal enfoque por si só escapa ao enrijecimento do classicismo ao qual o Édipo por vezes é relacionado: afirmar que torrentes eróticas do menino pelo pai fazem parte do processo normal de constituição da identidade masculina do menino remonta ao Complexo de Édipo denominado por Freud como invertido ou negativo e, notadamente, atribui maior relevância a ele que parece ter sido sempre legado mais ao desvio que à regra. A polaridade dos gêneros sempre representou o núcleo da formação do conflito edipiano, o que pode ser constatado inclusive por sua divisão em positivo e negativo que remete a um duplo, no caso dos meninos, filho-mãe, filho-pai (Blos, 1998). Porém, essa divisão parece ter deixado, por vezes, a impressão falaciosa de que a versão denominada "negativa" nem sempre se faz presente ou que, ainda, quando presente, é indicativo de um fracasso na identificação masculina do menino com o pai, o qual, em vez de ser alvo de sua rivalidade, é objeto de seu desejo. Ser homem é o que está em jogo no Édipo do menino: ser homem como o pai - por amá-lo e receber dele a transmissão da virilidade e, consequentemente -, ser o homem da mãe - mas isso não significa que tal conflito se resuma ao Édipo positivo.

Segundo J.-D. Nasio (2007), haveria "três movimentos fundadores do desejo masculino": possuir, ser possuído e suprimir. Esses três desejos fundamentais enraizados no Édipo podem encontrar objetos variados nas fantasias, mas, se expressam, em geral, como o desejo de possuir sexualmente 
o corpo da mãe, o desejo de ser possuído pelo corpo do pai, como, também, o desejo de suprimir o corpo do pai. Vejamos como o autor caracteriza esse segundo movimento:

Com efeito, o menino pode desempenhar o papel passivo, eminentemente feminino, de ser a coisa do pai e fazê-lo gozar. Mas devemos entender que, se a criança imagina-se seduzida, não apenas ela é vítima passiva de um pai perverso, malvado ou tarado, como também uma sedutora ativa que espera ser seduzida; a criança seduz para ser seduzida. (p.31-32)

Esse fragmento pode gerar incômodo uma vez que, no Édipo, o desejo do menino pelo pai é comumente confundido com o amor, provavelmente como vestígio da noção de linearidade do desenvolvimento da masculinidade. Não se trata, contudo, que essa diferença não tenha sido estabelecida pelo próprio Freud. Mais ao fim da obra freudiana, como no caso do "homem dos lobos" (Freud, 1918/2006), assim como em "Uma criança é espancada" (Freud, 1909/2006), é o complexo de Édipo negativo que adquire valor etiológico. Nesses artigos importantes, o valor teórico dominante indica uma longa e complexa história do desejo passivo de ser possuído pelo pai. No primeiro, diante da cena do coito dos pais, pode-se inferir do material clínico que Sergei se coloca tanto numa posição masculina que se identifica com o pai ativo e outra passiva, feminina, em que a identificação é materna. Em "Uma criança é espancada", a fantasia sexual consciente do menino e carregada de excitação sexual é a de que ele é surrado por uma mulher. Porém, essa fantasia remete ao estágio prévio, de ser espancado pelo pai, que permanece inconsciente. Trata-se da encenação do desejo de ser amado, segundo uma modalidade genital, pelo pai, enfim, do desejo de ser possuído pelo pai que caracteriza o Édipo negativo.

Desse modo, contudo, a sustentação do paradoxo intrínseco à constituição da masculinidade nos leva, a outra aparente contradição ou, ao menos, a um descompasso para com a compreensão usual. Para além do paradoxo, o que pode ser um impasse para a assimilação do desejo e das fantasias eróticas com os quais o menino deve envolver seu pai, é justamente a questão sobre como é possível identificar-se desejando possuí-lo em vez de amando-o e procurando ser como ele. Sem dúvida, há um distanciamento aí, mas não se trata de um processo que se dá por um paralelismo. Se pensarmos na argumentação de Bleichmar (2006) de que serão as fantasias, inevitavelmente significadas pelo Eu como homossexuais, o caminho para a masculinidade, mostra-se importante destacar a convicção daquilo que subjaz a tal posicionamento: a de que não há absolutamente possibilidade de tornar-se homem, ou mesmo mulher, se não for pela diferença. Em outras palavras, identidade se define, em primeira instancia, por oposição - no caso da masculinidade, em oposição ao feminino (Schneider, 2003) - e, depois, por afirmação. Sobre isso, alerta Bleichmar (2014):

Justamente, en la clínica psicoanalítica - muy particularmente la de niños -, se ha llegado a veces a la banalización de pensar que, para 
hacerse hombre, un niño necesita de un papá con el cual jugar y no de un papá que salga a pasar con la mamá, que duerma con ella o que haga estas cosas de un hombre: lo que esto muestra es el absurdo de creer que la identidad se produce por similitud y no por diferenciación. Es la alteridad la que define. (p.16)

Enfim, constatar que os eixos que compõem o Édipo abrigam extremos opostos constituindo uma passagem que caracteriza, mais que a ambivalência amor-rivalidade, forças paradoxais e dependentes como o amor, a rivalidade e o desejo pelo pai, provocou uma importante mudança de ênfase. A nova abrangência do complexo edípico colocou em jogo os desejos sexuais que se originariam em uma identificação dupla, feminina e masculina, sendo simultaneamente composto pelo aspecto positivo e negativo e configurando um conflito de cuja resolução depende a sexuação (Hornstein, 2009). Isso implicou, também, que uma maior atenção fosse dedicada às relações "isogenéricas" do Édipo as quais passaram a receber mais importância na clínica (Blos, 1998). No entanto, apesar dessa etapa positiva de integração entre as duas faces do Édipo que promove mais coesão entre identificações femininas e masculinas, destacamos que o movimento assim iniciado continuou a romper com outras divisões. Desse modo, a tendência psicanalítica atual é conceber esse processo como algo ainda mais múltiplo, diversificado e fluido, ou seja, menos marcado pela noção de uma identificação orientada pelo binarismo de gênero.

\section{UM CERTO PROTAGONISMO PATERNO}

Sobre o envolvimento do menino com o pai, devemos ressaltar que, apesar do notório protagonismo da mãe, não é exclusividade sua a sedução pulsante proveniente dos cuidados precoces que envolvem o menino. O pai, diante do corpo do filho, não ocupa apenas um lugar de interdição do gozo da mãe, mas, como metonímia da mãe, exercita ele mesmo um gozo auto-erótico (Bleichmar, 2006). Se, com a mudança de foco da pesquisa psicanalítica para as relações mais precoces do bebê, o Édipo foi ofuscado pela evidência dada ao papel da mãe pré-edipiana (Blos, 1998), também é justo afirmar que o papel do pai passou a ser compreendido, cada vez mais, como fundamental para o funcionamento psíquico, já que é o pai quem introduz a realidade entre mãe e filho (Breen, 1998).

É verdade que a passividade característica dos tempos mais elementares só pode ser experimentada como feminina a partir de uma re-significação a posteriori (Ribeiro, 2000), de modo que a passividade e a atividade estão em jogo muito antes de adquirirem uma significação sexuada para o sujeito em vias de constituição. No entanto, a relação excitante precoce entre pai e filho funcionará, no momento de sua significação perante a diferença sexual, como aporte libidinal para a identificação sexuada e para os desejos eróticos do menino por seu pai (Bleichmar, 2006). Por isso, alguns autores vindicam mais 
que um papel coadjuvante para o pai mesmo nesses momentos primordiais da relação "dual", ou seja, algo além de um pai que não está presente para a mãe e ausente para criança ou se fazendo, de alguma forma, presente apenas através do psiquismo materno. Ainda que agindo o pai, por vezes, como um substituto, afirma Blos (1998):

Parece-me que foi atribuída à mãe inicial uma participação demasiada e exclusiva para a sensação de integralidade corporal. Temos muitas oportunidades de observar, na análise de homens adultos, a influência persistente desta imago do pai, sobretudo quando ela se mantém inalterada pela realidade. . . . Através da literatura, têm-se a impressão de que o complexo negativo declina pela ascendência e subsequente resolução do complexo positivo ou, em outras palavras, que a configuração triádica totalmente desenvolvida efetua, através de sua súbita ascensão, a resolução ou transformação do complexo negativo. Naturalmente, todo analista sabe que não é este o caso. . .

Atualmente, estamos autorizados a dizer que a especificidade patogênica e qualitativa desta proximidade advém de uma perpetuidade inalterada da relação filho-pai, cujos princípios são encontrados em uma ligação, por substituição, quase materna. (p. 59)

Firmado na convicção da "perpetuidade" dessa relação é que Peter Blos (1998), no artigo "Filho e Pai", descreve a importância cabal que o envolvimento com o pai pré-edipiano terá para o menino até a re-atualização do Édipo na adolescência, em um desfecho complexo que, à semelhança da tese de Bleichmar em "Paradojas...", envolve fantasias que afirmam e ameaçam sua identidade. Para o autor, se no período pré-edipiano o pai servir apenas como substituto da mãe, pode-se esperar uma relação patogênica futura entre pai e filho; por outro lado, jaz no fato de o pai ser percebido e apropriado de forma diferente pelo filho, ser notado em sua especificidade, o florescer das potencialidades incipientes da criança.

O pai assume, para o menino, desde cedo, uma qualidade carismática diferente da mãe, por sua presença diferenciada, no que diz respeito a sua constituição e receptividade corporal. A qualidade respectiva à maneira como o pai ou a mãe segura o bebê, ou brinca com ele, demonstra bem a variedade ou a disparidade de que estou falando. . . . Tal pai, o diádico, foi chamado "não contaminado", pelo fato de nunca ter sido um parceiro simbiótico completo. Ele pertence ao estágio da idealização pré-ambivalente, pós-diferenciação, das relações iniciais de objeto. O ciúme é, de fato, notável, assim como a busca pela posse total do objeto. No entanto, a mudança do filho em direção ao pai ainda não é afetada ou comprometida por ciúme sexual, conflito patricida e ansiedade de retaliação. Esses choques emocionais pertencem ao pai da era edipiana. (p. 64)

Idealmente, em vez de uma entrada tardia do pai que vem ocupar seu lugar de direito, exercer a "função paterna" e que passa a ser visto pelo filho como objeto a seduzir e a odiar, sua presença já no período pré-competitivo lançaria as bases de confiança e segurança do menino em relação ao pai que, então, passa a ser restritivo no complexo edípico. Por ser assim, o menino, 
contando com o pai assegurador dos primórdios, não precisa ser dominado pelos delírios infantis edipianos, isto é, trata-se do elemento precursor do princípio de realidade (Blos, 1998). Entretanto, se o pai recebe sobre os ombros uma missão mais relevante, isto é, a de estar mais próximo ao "pai libidinal", que não é uma função simbólica apenas, mas uma presença masculina real e sedutora (André, 1996), as falhas ou excessos de sua presença repercutirão mais contundentemente. Segundo Blos (1998), a qualidade da relação que o pai disponibiliza ao filho já nos primórdios pode impor um grande obstáculo quando há, por parte do pai, uma necessidade excessiva de proximidade com seu bebê isogenérico, demonstrando que ele gratifica com seu filho a sua própria fome vital de pai. Assim, o autor assevera que:

Um envolvimento emocional dessa espécie sempre compreende uma rede de três gerações. Sob estes auspícios, uma ligação infantil, potencialmente libertadora, torna-se servidão opressora. Pode-se dizer que a abandonada teoria da sedução ressurge, aqui, num rumo inesperado e sob forma inesperada. Observei esse tipo de interação entre pai e filho analisando diversos homens que obtinham um prazer excessivo das tarefas envolvidas nos cuidados de seus bebês. Num dos casos, a criança respondeu à necessidade do pai passando a visitar sua cama todas as noites, sempre passando pela mãe. Nenhuma interferência disciplinar podia, agora, manter o menino de quatro anos em seu quarto, porque ele continuava respondendo aos desejos insistentes e inconscientes do pai pela proximidade física e emocional. Quando a privação do contato físico e emocional do paciente com seu próprio pai emocional emergiu, na análise, o menino passou a obedecer o pedido de ficar em seu quarto. As visitas noturnas à cama do pai desapareceram em função da percepção crescente, do paciente, de que ele gratificava de modo vicário sua própria "fome pelo pai" pré-edipiana, através da proximidade corporal com seu filho pequeno. (Blos, 1998, p. 68, grifo nosso)

Esse fragmento deve ser destacado tanto pelo elemento de sedução e do enlace erótico entre pai e filho que pode produzir uma falta tão contundente, quanto pelo aspecto da transmissão que coloca em evidência as marcas deixadas no pai pelas faltas ou excessos de seu próprio pai, que colocam a masculinidade, tal como propõe Bleichmar (2006), em uma rede de gerações. O Édipo sempre coloca em jogo, no estabelecimento de um laço atual, antepassados e descendentes, seja quando o pai projeta em seu filho o desejo de morte que uma vez ele projetou em seu pai ou quando deve transmitir ao filho, prova da função fálica de seu próprio pênis, os direitos de herança sobre seus dons para que os legue a outro filho ao aceitar se reconhecer como sucessor e ao reconhecer um sucessor aceita legar sua função (Hornstein, 2009).

\section{ADOLESCER HOMEM: A RE-ATUALIZAÇÃO DO PARADOXO}

Entre os estudos psicanalíticos sobre adolescência, parece haver um consenso de que se trata de um momento que vem romper com o período de 
latência e conjurar as fantasias envolvendo os personagens do Édipo até certo ponto sepultados. A re-atualização do complexo de Édipo, então, coloca em primeiro plano essa questão entre o antigo e o novo, ou melhor, de um conteúdo familiar que, inserido em um contexto atual, ganha roupagens totalmente novas e já não parece tão conhecido. Portanto, agora que viemos até aqui, perpassando os momentos essenciais que comporiam o processo de constituição da identidade masculina de um menino em sua relação com o pai, surge a indagação: o que representa a adolescência para a masculinidade enquanto momento cronologicamente posterior ou, em alguns sentidos, final?

Segundo Bleichmar (2006), a metamorfose da puberdade não pode ser entendida como o ápice de um processo linear que atravessa os três momentos da constituição da masculinidade descritos por ela. Logo, novamente mostra-se condicional para a apreensão adequada do processo de formação identitária reconhecer a especificidade dos diferentes tempos que se sucedem, assim como a integração entre eles que, devido às re-significações por après-coup, se sobrepõem e se determinam sequencial e retroativamente. Por isso, o caminho trilhado até o adolescer do menino possui, como já vimos, importância legítima, mas não pode ser absolutamente determinante na assunção da genitalidade e identidade adulta. Na chegada ao momento em que é confrontado com a possibilidade real do exercício da eleição de objeto de amor, "una complejidad predeterminada se encontrará con algo del acontecimiento, de lo azaroso, que coagulará en cierta dirección las dominancias posibles." (Bleichmar, 2006, p. 31).

Talvez seja essa a justificativa para o fato de que em "Paradojas de la sexualidad masculina" (2006) Bleichmar não trate sobre a puberdade e a adolescência a não ser em menções pontuais: é preciso manter a abertura porque não há como determinar. Com efeito, o encontro descrito acima por Bleichmar entre o pré-determinado (a puberdade), o incerto e as dominâncias parecem indicar uma direção adequada, ainda que inconveniente ao desejo de traçar uma lógica rígida "se $x$, então $y$ ". A falácia desse enquadramento artificial da puberdade como simples reflexo das "etapas" denuncia que, apesar de cada momento do processo constitucional ter papel sui generis e que a eficácia ou as falhas em cada um deles ter consequências específicas impactando inevitavelmente as vivências futuras, não são determinantes da puberdade uma vez que este momento posterior re-significará as vivências anteriores.

Por isso, é preciso lançar, mais uma vez, um olhar renovado para a relação entre filho e pai. Segundo Peter Blos (1998), partindo de sua profunda experiência com adolescentes, a ideia de uma solução tardia do complexo de Édipo negativo na adolescência parece explicar o conflito nuclear dos meninos adolescentes. Para o autor, que, como já tratamos, defende a fusão do pai edipiano com o pai dos cuidados primordiais, estando enraizado já no estágio dual das relações de objeto que se caracterizavam pela alternância entre submissão, afirmação e o compartilhar da grandeza do pai, o Édipo negativo 
permaneceria reprimido, em um estado quase inalterado, até a adolescência, quando atingiria o ápice de sua conflituosidade. Por essa razão, defende:

Não é incomum . . . que impulsos libidinosos isogenéricos surjam depois de passada a relativa calma dos anos de latência. Estes anseios não representam, à primeira vista, uma inclinação ou disposição homossexual, mas confirmam, isso sim, que a formação adolescente normal da identidade sexual masculina está em andamento. (Blos, 1998, p.63, grifo nosso)

É interessante notar que o trecho citado remete à tese de Bleichmar em "Paradojas...": uma ligação entre filho e pai que pode ser significada como homossexual, quando, na realidade, é parte de um processo normal e legitimador da identidade do menino. Ainda que com uma tese que, em aspectos importantes, se distancia da de Bleichmar, Blos também se aproxima da autora nesse sentido fundamental. Para o autor, a resolução do conflito edipiano negativo, que abriga essas moções desejantes em relação ao pai, intervém positivamente na "atividade heterossexual compulsiva, desregrada, ou, inversamente, a incitação de ansiedade, devido à inação ou passividade heterossexual" (Blos, 1998, p. 61) dos adolescentes.

O grande conflito do menino na adolescência parece ser, portanto, bem uma re-atualização daquilo que Bleichmar (2006) se referiu como paradoxo da sexualidade masculina. O menino deve buscar o pai amoroso e amado, uma empreitada libidinosa que entraria em choque com cada fato da vida emocional do menino, fazendo com que, paradoxalmente, como uma defesa identitária diante desses enlaces significados como homossexuais, tenha uma postura comum de auto-afirmação e de oposição perante o pai (Blos, 1998).

o movimento rápido do rapaz adolescente em direção ao pai,
manifestado defensivamente pela oposição e pela agressão, é
geralmente coincidente com a intensidade e urgência da necessidade
do filho por uma proximidade protetora dele frente à mulher
magnética e misteriosa por quem ele é misteriosamente atraído. Esta
constelação de impulsos é, com freqüência e rapidez excessivas,
identificada como homossexualidade; uma equação tão simplista
exige uma vigorosa contestação. O que observamos é a luta
defensiva do homem contra a passividade em geral, não contra a
homossexualidade em especial. . . . Afinal, a adolescência é o estágio
da vida em que as polaridades universais de ativo e passivo estão em
conflito e em um combate final de proporções prometéicas. Na
análise do rapaz adolescente, é imperativo que esta luta defensiva
duplamente facetada - contra a submissão e a passividade bem como
contra a auto-afirmação e o parricídio - seja destrinchada. (Blos,
1998, p.62, grifo nosso)

Na adolescência, quando a última chamada à apropriação sexual se faz ouvir, o sujeito não pode desvencilhar o momento crítico do seu processo identitário do objeto de amor - também por isso é que passividade e atividade se mostram tão polarizadas. Para além do conflito já citado entre buscar o pai, em uma posição passiva, e opor-se a ele em uma atitude defensiva do que acaba sendo significado como homossexual e conflitante, é notável que Blos (1998) 
trace outro paralelo entre a agressividade para com o pai e a atração pela mulher. Como duas grandezas diretamente proporcionais, na medida em que o menino mais se sente convocado a assumir uma posição sexuada perante o objeto, a oferecer seu pênis como exercício de prazer indissociável de sua identidade viril, mais se opõe ao pai. Talvez, seja nesse ponto em que se possa ver a re-atualização acontecer. Não se trata do mesmo momento anterior da constituição em que a proximidade inquietante com o pai precisava acontecer: enquanto adolescente, a convocação do real do sexo reativa a transmissão paterna legitimadora, porém, agora, deve ela ser sepultada. A incorporação da masculinidade, que aponta para as fantasias eróticas do menino por seu pai do período pré-edipiano até a adolescência, deve, então, deixar apenas vestígios cujos fantasmas podem, aí sim, dependendo da bagagem de todo processo até a puberdade, ser mais ou menos aterrorizadores para o "Eu masculino".

Por fim, encontra-se na tese ousada de Peter Blos (1998) uma contribuição importante e que encontrou algum sentido junto à de Silvia Bleichmar (2006). Ainda assim, é preciso reconhecer que o autor atribui demasiada importância ao pai das relações primordiais, ao ponto de considerar que a resolução do complexo de Édipo depende da resolução da relação com o pai pré-edipiano. Afinal, se há uma diferença qualitativa entre os cuidados exercidos pelo pai com o bebê, isso não pode suplantar a presença do pai sexuado, ator principal absoluto nas teorizações de Bleichmar, mas que parece secundário para Blos. O processo identificatório do menino com seu pai, que coloca em jogo uma transmissão sexual que um possui e outro quer possuir, e o próprio paradoxo dessa relação que, de forma menos explícita, parece compor a tese de Blos (1998) precisa evidenciar a posição sexuada, tanto do pai, o detentor, quanto do menino, o aspirante.

\section{SEDE DE PAI: O ENIGMA QUE PEDE RESOLUÇÃO}

O caráter paradoxal introjetivo da incorporação descrita por Bleichmar se sustenta, como já elucidamos, sobre o fato de condenar para sempre a masculinidade ao fantasma da homossexualidade (graças ao efeito atormentador da incorporação do pênis paterno e de todas as vicissitudes da relação que se desenrola entre filho e pai desde os primórdios), mostra seu sentido na promoção de uma função identitária que não se restringe aos anos em que uma criança pode estar imersa em laços eróticos e fantasias edipianas com seu pai. Isso significa que, por meio da instauração do fantasma paradoxal, são inaugurados caminhos que não estão isentos de inquietação, mas, ainda assim, conduzem o menino a diversos horizontes possíveis para sua conformação identitária sexuada.

Por outro lado, a falha desse processo representará um grande impasse na constituição identitária em que o sujeito pode se ver preso em um trajeto "curto- 
circuitado", ao longo do qual traça um curso viciado na busca de respostas para o enigma mortificante que a identidade sexuada lhe impõe. Logo, a faca de dois gumes que é a confirmação da identidade do homem acompanhada pela produção de uma fantasmatização paradoxal é um "mal" necessário e menor diante do impacto provocado por sua ausência. Não ter seu sexo revestido de potência por um homem amado deixará o menino - e, futuramente, o homem submetido à busca desesperada pelo real faltante ou a mercê de solucionar o enigma que impede que masculinidade seja plenamente integrada ao Eu (Bleichmar, 2006). Em outras palavras, poderíamos dizer que a incorporação eficaz é a forma de saciar a sede que todo menino sentirá de pai, ou do homem amado, para poder assumir uma identidade masculina sexuada.

Bleichmar (2006) descreve um caso que elucida essa situação de falta e que, como veremos, lança luz sobre um contexto de vulnerabilidade que pode ter graves implicações. Tendo retornado à Argentina depois de anos de exílio pelo regime militar, a autora conta ter recebido a ligação de Esteban, um dos pacientes que tiveram o tratamento interrompido na ocasião da debandada de sua terra natal. Após todos aqueles anos, Esteban declarou estar determinado a Ihe contar o que não fora capaz de revelar na época de seu tratamento, fatos que, segundo ele, também não pôde abordar em suas tentativas pontuais de retomar o processo analítico com outros profissionais. Então, em seu reencontro com Bleichmar, o paciente Ihe relatou duas experiências passadas cujas marcas nele deixadas são notáveis pela dificuldade que teve para poder falar delas.

Primeiramente, Esteban contou-lhe sobre um acontecimento de sua adolescência: quando tinha 13 anos, um grupo de rapazes do bairro, maiores do que ele e a quem admirava, o levaram para um lugar afastado e, com certo nível de consentimento por parte dele, abaixaram suas calças e tocaram o ânus de Esteban com seus órgãos penianos. Tal cena, vivida com intensa humilhação, ele relaciona a uma prática que nunca havia revelado, isto é, sua compulsão por masturbar-se analmente com objetos, esfregando-os em seu ânus, sem penetrálo. Esteban conta que, apesar de feliz em seu casamento e de sua satisfação com suas relações sexuais maritais, é tomado pela vergonha diante de sua necessidade de masturbar-se desse modo logo após fazer sexo com sua esposa, como se o ato só assim estivesse consumado. Já o outro episódio que havia relutado em contar à analista referia-se a um acontecimento de sua infância quando seu tio, pertencente a uma facção política contrária a de seu pai, invadiu sua casa violentamente em busca do cunhado. Segundo Esteban, seu pai, temendo por sua vida, fugiu pelos fundos da casa após clamar à esposa que intercedesse em seu favor diante do irmão. Nessa recordação de Esteban, tão marcante para ele, o mais terrível foi ter testemunhado seu pai pedir proteção à esposa, ter "se escondido sob as suas saias".

A elaboração teórica de Bleichmar sobre a masculinidade nos adverte que, diante de associações como essas, é imprescindível que o analista possa 
controlar seu impulso de seguir a via interpretativa tradicional entendendo o conteúdo angustiante como sendo diretamente vinculado a uma "homossexualidade inconsciente" ou, ainda, aos resquícios de uma bissexualidade psíquica. Resistindo a esse ímpeto é que esse conteúdo do discurso do paciente poderá ser integrado aos elementos próprios à masculinidade em vez de legado a elementos vestigiais e estrangeiros à identidade. Com efeito, mantendo essa escuta é que a segunda questão revelada por Esteban à Bleichmar pode ser integrada à primeira. Não passou despercebidamente aos olhos da analista que ambos episódios, descritos após anos de acúmulo de força e coragem, conjugavam situações que colocavam em risco a representação que Esteban tinha sobre sua própria masculinidade e testemunhavam sobre seu aspecto falido. Bleichmar percebe que 0 ato abusivo com o qual Esteban em algum nível concordou, além de levar ao sintoma compulsivo devido à inscrição erótica que demanda a repetição da excitação, remete à sua tentativa frustrada de suprir a falta deixada pela representação insuficiente deixada pelo pai como indica o sentido que tem para ele a cena de fuga.

Su aceptación de la seducción ejercida por los majores . . . se sostenía sobre la siguiente paradoja: al poner en lo manifestó, en acto, una corriente supuestamente homosexual de la vida erótica, ésta estaba al servicio de una búsqueda de masculinización, de una suerte de resolución imposible - de ahí el carácter sintomático que tomó a lo largo de la vida - de la masculinidad fallida del padre que cobraba la fuerza de una escena paradigmática en el recuerdo de la huida por los fondos de la casa escudado "en las faldas" de la madre. (Bleichmar, 2006, p. 66, grifo nosso)

Nesse sentido, o conflito e o paradoxo da identidade masculina mostram seu ápice. Na busca por sanar o "enigma da masculinidade" devido à falta simbólica fundamental em sua amarração identitária, isto é, de ter seu órgão masculino revestido por uma virilidade legitimadora, foi que Esteban aquiesceu diante da oferta abusiva dos rapazes mais velhos que exibiam a imagem da masculinidade que ele mesmo gostaria de possuir. O que ele buscava era a transmissão no real daquilo que o pai castrado, covarde em sua percepção de filho, não pôde lhe oferecer simbolicamente. Em outras palavras, buscava tornarse plenamente masculino a partir do pênis do outro e, com esse intuito, participa da cena que acaba significada pelo Eu como resultado de uma "complacência homossexual" que, por fim, contraria o motivo de tudo isso e acaba representando um entrave a sua percepção de si enquanto homem. Além disso, a excitação gerada nesse episódio fatídico parece ter encontrado uma via de ligação justamente com o desejo e o imperativo de incorporação, de modo que a compulsão masturbatória amarra-se tanto à busca de virilização quanto às marcas traumáticas deixadas por sua vulnerabilidade no afã de encontrar solução para o enigma de sua identidade sexuada (Bleichmar, 2006). 
É também nesse sentido que Bleichmar (2006) apresenta o caso de Nathanael que, com apenas sete anos de idade, coloca em jogo os extremos a que pode levar o desejo de masculinização diante da identificação masculina falida mesmo na infância. O pequeno paciente foi levado à analista quando tinha cinco anos de idade devido, segundo ela, a um conjunto de transtornos como usar chupeta em todos os lugares, enurese, seu gosto por fantasiar-se de princesas, além da observação da analista de que estava preso em uma relação simbiótica com a mãe. Após dois anos de tratamento, quando, pelas questões iniciais já se mostrarem satisfatoriamente resolvidas, apesar de ter a convicção de que alguns enigmas ainda não haviam sido elucidados, Bleichmar encerrou o processo analítico de Nathanael. Entretanto, oito meses após a finalização, a mãe do menino telefonou aflita para a analista assim que ele Ihe confidenciou um fato ocorrido - o que, segundo Blechmar (2006), veio, enfim, dar sentido ao material apresentado que a analista não havia, à época, conseguindo compreender. Nathanael contou que, já há algum tempo, um primo de doze anos de idade o prendera no banheiro e o sodomizara. Segundo o menino, ele não reagiu e manteve segredo de todos por temer a retaliação do agressor, mas Bleichmar (2006), já a par da história de Nathanael, do papel faltante de seu pai e dos seus conflitos identitários, conseguiu lançar um olhar surpreendente sobre sua submissão sem resistência:

El enigma de la masculinidad, la ausencia de padre capaz de saldar esta falla en la estructuración simbólica, lo había llevado a ceder al otro sin que pudiera rebelarse ni reconocer el goce secreto experimentado. Se trataba de un verdadero acto de búsqueda de resolución del "enigma de la masculinidad", un ritual de penetración al cual, habiéndose pasivamente entregado al inicio a la búsqueda de compensación en lo real de una falla en la incorporación representacional del atributo de potencia, regresaba una y otra vez en una reiteración traumática de lo real vivido que coagulaba, desde una perspectiva paradójicamente homosexual, su deseo de recibir el atributo de una masculinidad cuyo padre parecía negarle. (p. 38-39)

Consideramos essa espécie de "entrega" a casos de violência ou "aceitação da sedução" tanto no caso de Esteban quanto no de Nathanael, enquanto reflexo de uma falta no processo constitucional da identidade de meninos, uma constatação de importância revolucionária. A possibilidade de entender que a sede de pai deixada pela transmissão ineficaz da masculinidade pode legar sujeitos à extrema vulnerabilidade de submeter-se a qualquer situação que possa simular, mesmo que remotamente, a incorporação falida é extremamente alarmante. Aliás, se o "declínio do pai" tem sido anunciado por psicanalistas há décadas, o que pode isso significar para a constituição da masculinidade e para as práticas sexuais dos homens tendo em vista uma hipotética condição generalizada de fragilidade e busca por legitimação na atuação de uma fantasmática de incorporação? 
O livro "Not gay: sex between straight white men" (Ward, 2015) aborda, além do contexto militar, a submissão sexual de calouros de universidades estadunidenses aos veteranos da fraternidade da qual querem fazer parte. Os "trotes" por vezes incluem práticas tradicionais como o "elephant walk", na qual cada homem segura com uma mão o pênis do que está atrás de si e insere a outra no ânus do que está a sua frente, e o "circle jerk" em que os homens se sentam em uma roda e masturbam uns aos outros. Mais ainda, ao realizar a pesquisa "straight pledges sex" no Google por vídeos, é possível encontrar várias cenas humilhantes de "estupro voluntário" que acabam em sites de vídeos pornográficos. Na maioria das situações, os calouros ("pledges") são obrigados a ficarem pelados, a praticarem felação mútua e até sexo anal uns com os outros e, em outras, os próprios veteranos, no papel ativo de humilhação, participam do ato sexual, recebendo sexo oral e sodomizando os aspirantes à fraternidade.

Tudo isso significa que rapazes, que parecem submetidos a um estereótipo de virilidade heterossexual em que a relação com outro homem é humilhante, estabelecem um ciclo em que todos os membros de um grupo masculino passaram por relações dessa natureza e, em muitos casos, ao menos diante da chegada de novos calouros, permaneceram tendo relações homossexuais, porém, ocupando um lugar "ativo" que também os permite gozar sadicamente. Seria esse acordo, a que se submetem aparentemente contrariados, mantido pelo pacto silencioso entre rapazes que procuram suprir a mesma falta da incorporação? Ademais, tratar-se-ia de um fenômeno que expressa os efeitos generalizados do tão profetizado declínio do pai em relação à identidade masculina? Essas questões mostram-se relevantes também diante da conjectura que lança Lattanzio (2011) sobre o fenômeno pornográfico em que, segundo o autor, as práticas que envolvem sexo anal e oral são as preferidas entre os homens que consomem esse tipo de produto:

Haveria nessa preferência uma indicação da identificação dos homens com quem está sendo penetrada, dado que eles também têm ânus e boca? Pensamos que o desejo inconsciente de ser penetrado pode ser compreendido aí como traduzido/simbolizado e recalcado por essa forma tão difundida de fantasia sexual masculina. (p. 122)

Dentre diversas questões que podem ser evocadas por essas hipóteses, destacamos uma que nos parece mais alarmante, isto é, em relação ao abuso sexual de meninos e rapazes, uma realidade que, segundo Richard Gartner (1999, p. 29, tradução nossa) é "comum, sub-reportada, pouco reconhecida e pouco tratada". Esse reconhecido psicanalista especializado no tratamento de homens abusados sexualmente na infância, em relação às pesquisas que teriam constatado que meninos violados sexualmente estariam quatro vezes mais propensos a terem práticas homossexuais na vida adulta, lança a seguinte indagação: seria esse fato o efeito de uma causa, ou seria que os meninos que já apresentam uma orientação homossexual, por seu sentimento de inadequação e 
isolamento, estariam mais vulneráveis às investidas sexuais? (Gartner, 1999). Partindo desse mesmo elemento destacado pelo autor, a fragilidade identitária, poderíamos elaborar outra questão: não estariam os meninos, inseguros pela falta de um referencial simbólico consistente que afirme sua posição masculina, mais acessíveis à aproximação abusiva dos homens?

Sabemos que questões como essa podem evocar um saudosismo de tempos em que a presença do "pai forte" teria sido mais palpável e no qual as identidades teriam gozado de referenciais rígidos. No entanto, a fluidez das identidades de gênero, tão categórica na contemporaneidade, coloca em questão os enunciados sobre masculinidade e feminilidade advogando existirem, nesse contexto de um "pai enfraquecido", muitas possibilidades de ser homem. Aliás, trata-se de um aspecto que parece alinhar-se bem com o terceiro estádio descrito por Bleichmar, mas pouco explorado em "Paradojas de la sexualidad masculina",ou seja, aquele em que o menino, já tendo legitimado sua posição sexuada, tem diante de si uma escolha sobre qual "classe" de homens ele pode integrar. Mais que uma simples opção, todavia, como elucida Bleichmar (2014) em outra obra, o caminho a percorrer parece depender do conflito desempenhado pelo paradoxo no núcleo da identidade masculina, uma vez que esta, quanto melhor afirmada, menos defensivo poderá ser homem e, por conseguinte, mais amplas e fluídas poderão ser as fronteiras do que referencia sua virilidade.

Portanto, o que evidenciamos, talvez, refira-se mais especificamente a apenas essa "classe" masculina que, sim, tal qual o paradigma que sustenta a tese defendida por Bleichmar, depende de um referencial paterno rígido (também assombrado por um paradoxo) para revestir uma identidade marcada pela fragilidade e que se mantém, ela mesma, às custas de um enrijecimento. Havendo verdade nessa conjectura, muito mais que um puro saudosismo, a vulnerabilidade dos meninos, rapazes e homens em busca da solução do enigma de sua posição sexuada em tempos marcados pelo declínio da imago paterna mostra-se digna de atenção como um possível conflito, paradoxal e propriamente masculino, da pós-modernidade ou de uma possível "transição" que vemos acontecer. Afinal, a desconstrução do modelo masculino rígido ameaça a manutenção dessa "classe" que, em meio à diversidade contemporânea, ainda resistiria, mas que não está imune às angústias e às atuações que adviriam do desintegrar de seus referenciais simbólicos.

Finalmente, todas essas questões são lançadas na expectativa de que um olhar atento aos conflitos intrínsecos à complexidade do processo de tornar-se homem possa não apenas encontrar respostas, mas também iluminar tantas dessas nuances nebulosas dos paradoxos da masculinidade na atualidade. A tese defendida em "Paradojas de la sexualidad masculina" é digna do mérito de compor a inauguração de um movimento que denuncia a insuficiência retumbante da teoria da castração, da bissexualidade psíquica e, principalmente, 
do falocentrismo para a escuta e apreensão da subjetividade masculina. Desse marco em diante, é preciso avançar, porém, mantendo a mesma intrepidez para reconhecer a insuficiência da teoria reformulada diante do que a clínica, ao longo dos anos, nos confronta e, principalmente, em relação àquilo que é constantemente afetado pela transformação dos modos de subjetivação e aos paradigmas que sustentam o que significa ser homem.

\section{DECLARAÇÃO DE CONFLITOS DE INTERESSE}

Os autores declaram que conceberam e contribuíram efetivamente na realização deste artigo. Tornam pública a responsabilidade pelo seu conteúdo, que não foram omitidas quaisquer ligações ou acordos de financiamento entre os autores e companhias que possam ter interesse na publicação deste artigo. Afirmam que não têm qualquer conflito de interesse com o tema abordado no artigo. Declaram que o artigo citado acima é original e que o trabalho, em parte ou na íntegra, ou qualquer outro trabalho com conteúdo substancialmente similar, não foi enviado a outro periódico científico e não o será.

\section{REFERÊNCIAS}

André, J. (1996). As origens femininas da sexualidade. Rio de Janeiro, RJ: Jorge Zahar.

Bleichmar, S. (2006). Paradojas de la sexualidad masculina. Buenos Aires: Paidós.

Bleichmar, S. (2010). Psicoanálisis extramuros: puesta a prueba frente lo traumático. Buenos Aires: Editorial Entreidas.

Bleichmar, S. (2014). Las teorías sexuales en psicoanálisis. Buenos Aires: Paidós. Blos, P. (1998). Filho e Pai. In: Breen, D. (Org.). O enigma dos sexos. Rio de Janeiro, RJ: Imago (Trabalho original publicado em 1982).

Breen, D. (1998). Introdução Geral. In: Breen, D. (Org.) O enigma dos sexos. Rio de Janeiro, RJ: Imago.

Freud, S. (1918/2006). História de uma neurose infantil. Rio de Janeiro, RJ: Imago. (Edição Standard Brasileira das Obras Psicológicas Completas de Sigmund Freud, v.XVII, Trad. Jayme Salomão).

Freud, S. (1919/2006). 'Uma criança é espancada': uma contribuição ao estudo da origem das perversões sexuais. Rio de Janeiro, RJ: Imago. (Edição Standard Brasileira das Obras Psicológicas Completas de Sigmund Freud, v.XVII, Trad. Jayme Salomão).

Freud, S. (1923/2006). O Ego e o Id. Rio de Janeiro, RJ: Imago. (Edição Standard Brasileira das Obras Psicológicas Completas de Sigmund Freud, v.XIX, Trad. Jayme Salomão). 
Gartner, R. B. (1999). Betrayed as Boys: psychoanalytic treatment of sexually abused men. New York, NY: The Guilford Press.

Hornstein, L. (2009). Narcisismo: autoestima, identidade, alteridade. São Paulo, SP: Via Lettera.

Lattanzio, F. F. (2011). O lugar do gênero em psicanálise: da metapsicologia às novas formas de subjetivação (Dissertação de mestrado). Universidade Federal de Minas Gerais, Belo Horizonte.

McDougall, J. (1989). Narciso à procura de uma nascente. In: McDougall, J. Em defesa de uma certa anormalidade. Porto Alegre, RS: Artes Médicas.

Miguelez, N. B. S. (2012). Complexo de Édipo. (2a Ed.). (Coleção Clínica Psicanalítica). São Paulo, SP: Casa do Psicólogo.

Nasio, J.-D. (2007). Édipo: o complexo do qual nenhuma criança escapa. Rio de Janeiro, RJ: Zahar.

Ribeiro, P. C. C. (2000). O problema da identificação em Freud: recalcamento da identificação feminina primária. São Paulo, SP: Escuta.

Schneider, M. (2003). Genealogía de lo masculino. Buenos Aires: Paidós.

Ward, J. (2015). Not gay: sex between straight white men. Nova York, NY: NYU Press.

Sobre os autores

André Assis Breder Oliveira é psicólogo e mestre em psicologia pela Universidade Federal de Minas Gerais. Atualmente, é docente do curso de medicina do Centro Universitário de Várzea Grande (UNIVAG) e do curso de psicologia da Universidade de Cuiabá (UNIC). andrebrederoliveira@gmail.com

Cassandra Pereira França é pós-doutora em psicologia clínica e docente de graduação e pós-graduação do departamento de psicologia da UFMG. É coordenadora do Curso de Especialização em Teoria Psicanalítica da UFMG e do Projeto CAVAS/UFMG (Projeto de pesquisa e extensão com crianças e adolescentes vítimas de abuso sexual). O último de seus livros publicados sobre violência sexual é "Ecos do silêncio: reverberações do traumatismo sexual". cassandrapfranca@gmail.com

Certificamos que todos os autores participaram suficientemente do trabalho para tornar pública sua responsabilidade pelo conteúdo. A contribuição de cada autor pode ser atribuída como se segue: André Assis Breder de Oliveira e Cassandra Pereira França contribuíram para a conceitualização, investigação e visualização do artigo. André Assis Breder de Oliveira fez a redação inicial do artigo (rascunho) e André Assis Breder de Oliveira e Cassandra Pereira França são os responsáveis pela redação final (revisão e edição). 
Aceito: $01 / 11 / 2017$ 